Western University

Scholarship@Western

Biology Publications

Biology Department

$10-1-2016$

\title{
Editorial overview: Global change biology: Linking pattern and process to prediction and policy.
}

Vladimir Koštál

Brent J Sinclair

Follow this and additional works at: https://ir.lib.uwo.ca/biologypub

Part of the Biology Commons

Citation of this paper:

Koštál, Vladimir and Sinclair, Brent J, "Editorial overview: Global change biology: Linking pattern and process to prediction and policy." (2016). Biology Publications. 86.

https://ir.lib.uwo.ca/biologypub/86 


\section{EDITORIAL OVERVIEW}

\section{Global Change Biology: Linking pattern and process to prediction and policy}

Guest Editors: Vladimir Koštál* and Brent J. Sinclair ${ }^{\dagger}$

*Institute of Entomology, Biology Center, Czech Academy of Sciences, Czech Republic

'Department of Biology, University of Western Ontario, London, ON, Canada

Human impacts on the environment are now so substantial that geologists have proposed a new epoch, the Anthropocene [1]. Insects drive ecological processes in most of the terrestrial and freshwater habitats on Earth. Because of their ecological, economic, and biodiversity importance, the responses of insects to changing climate are a critical component to predicting its consequences. However, the diversity of insects makes this prediction very challenging. In this section of COIS, we address the complex problems of why insects are affected by global change, and how we can predict and manage insect responses.

There is mounting evidence that insect populations and distributions are changing substantially, and that those changes can be attributed to climate change [2]. These changes are likely forced by a combination of factors, including temperature, which affects insects as ectotherms in terms of both survival (see also [3]) and phenology (see [4]). As well as direct effects on insects, climate change can also have indirect effects, and Verheggen et al. [5] outline the ways by which climate change may affect insect pheromonal communication. There are, of course, a number of other physiological parameters that may be affected by climate change and which are not captured here, ranging from pollutants and toxicants [6], to shifting water balance and availability [7], to changing winter conditions [8] or impacts on migratory routes or behaviour [9]. 
A particularly sobering thought is that many of these stressors are changing (and increasing) in combination as a consequence of global change, which means that an understanding of each stressor in isolation will not suffice. Kaunisto et al. ([10]; disclosure: one of us [BJS] is an author on this paper) consider how best to approach this issue. They focus primarily on how to determine if stressor interactions are generalizable (i.e. can be extrapolated beyond a specific study system) and predictable (i.e. can the interactions of novel stressor combinations be predicted a priori based on previous knowledge).

Predicting the impact of global change is essential for managing insect population responses - whether for medical, agricultural, forest, or conservation purposes. Most predictive approaches have their advantages and shortcomings [11, 12]; Lobo [13] examines the use of ecological niche models, and advocates placing renewed emphasis on presence (as opposed to absence) data; after all, absence of evidence is not evidence of absence, and beyond a few well-collected taxa and localities, we cannot be certain that the search effort justifies the certainty that some algorithms place on reports of 'absence'. By contrast, Maino and colleagues [14] advocate a mechanistic approach to predicting the effects of climate change. Mechanistic models are intrinsically appealing because, unlike ecological niche models which rely on the quality of data input to generate future distributions, mechanistic models are based on parameters from individual insects. Maino et al. [14] caution, however, that mechanistic models still require abundant and detailed input data, and cannot yet deal with the issues of multiple interacting stressors, which are implicit in ecological niche models. The macrophysiological approach [15], which derives predictions from global-scale patterns, is not addressed in this section, but we note that it risks assuming the weaknesses of both the niche models (which lack precision) and the mechanistic models (which are acutely dependent on input data quality). Perhaps the important take-home message for all of these approaches is that they are best assessed with a clear and open understanding of their limitations and 
advantages; we note that there is no particular reason that risks should be assessed based on only one approach.

Finally, global change is a large-scale problem, which means that even if we can predict the responses of insects to climate change, the ultimate responsibility for action lies at the level of policy development and implementation. Hellmann et al. [16] tackle the difficult (for ivory-tower-bound scientists) issue of how science can influence that policy. They point out that climate change will take place over a large geographic scale, requiring a shift toward collaborative and interdisciplinary approaches, and new, process-based, prediction frameworks that lead directly to management recommendations. In turn, managers need to be willing to make evidence-based modifications to management practices make use of this new information. Most critically, however, Hellmann et al. [16] emphasise that scientists must be willing to engage with stakeholders, society, and politicians, both to ensure that their conclusions (and their uncertainties) are adequately understood, and to help identify and advocate for evidence-based policies that will avoid exacerbating the impacts of climate change on insects, ecosystems, and society.

Our focus in assembling this issue has been on understanding the drivers of responses to climate change (we are, after all, both physiologists) and putting these mechanisms into the context of making recommendations. We hope that this collection of articles will spark ideas among the readers - not just for their own research, but for how their research can interface with the goals of researchers operating at different levels of organisation, geography, or political influence.

We thank all the authors in this issue, and extend particular gratitude to the reviewers.

\section{References}

[1] Lewis SL, Maslin MA. Defining the Anthropocene. Nature 2015; 519:171-180. 
[2] Boggs CL. The fingerprints of global climate change on insect populations. Curr. Opinion Insect Sci. 2016.

[3] Sørensen JG, Kristensen TN, Overgaard J. Evolutionary and ecological patterns of thermal plasticity in Drosophila: Is it important for keeping up with climate change? Curr. Opinion Insect Sci. 2016.

[4] Forrest JRK. Complex responses of insect phenology to climate change. Curr. Opinion Insect Sci. 2016.

[5] Boullis A, Detrain C, Francis F, Verheggen F. Will climate change affect insect pheromonal communication? Curr. Opinion Insect Sci. 2016.

[6] Köhler HR, Triebskorn R. Wildlife Ecotoxicology of Pesticides: Can We Track Effects to the Population Level and Beyond? Science 2013; 341:759-765.

[7] Chown SL, Sørensen JG, Terblanche JS. Water loss in insects: An environmental change perspective. J. Insect Physiol. 2011; 57:1070-1084.

[8] Williams CM, Henry HAL, Sinclair BJ. Cold truths: how winter drives responses of terrestrial organisms to climate change. Biol. Rev. 2015; 90:214-235.

[9] Zipkin EF, Ries L, Reeves R, Regetz J, Oberhauser KS. Tracking climate impacts on the migratory monarch butterfly. Glob. Change Biol. 2012; 18:3039-3049.

[10] Kaunisto S, Ferguson LV, Sinclair BJ. Can we predict the effects of multiple stressors on insects in a changing climate? Curr. Opinion Insect Sci. 2016.

[11] Buckley LB, Urban MC, Angilletta MJ, Crozier LG, Rissler LJ, Sears MW. Can mechanism inform species' distribution models? Ecol. Lett. 2010; 13:1041-1054.

[12] Buckley LB. Get real: putting models of climate change and species interactions in practice. Ann. NY Acad. Sci. 2013; 1297:126-138.

[13] Lobo JM. Bioclimatic models and climate change predictions for insects. Curr. Opinion Insect Sci. 2016.

[14] Maino JL, Kong JD, Hoffmann AA, Barton MG, Kearney MR. Mechanistic models for predicting insect responses to climate change. Curr. Opinion Insect Sci. 2016.

[15] Gaston KJ, Chown SL, Calosi P, Bernardo J, Bilton DT, Clarke A, Clusella-Trullas S, Ghalambor CK, Konarzewski M, Peck LS et al. Macrophysiology: A Conceptual Reunification. Amer. Nat. 2009; 174:595-612.

[16] Hellmann JJ, Grundel R, Hoving C, Schuurman GW. A call to insect scientists: challenges and opportunities of managing insect communities under climate change. Curr. Opinon. Insect Sci. 2016. 